\title{
Razones para recomendar la vacunación contra el dengue en Isla de Pascua. Opinión del Comité de Inmunizaciones de la Sociedad Chilena de Infectología
}

\author{
Alberto Fica, Marcela Potin, Gabriela Moreno, Liliana Véliz, Jaime Cerda, Carola Escobar y Jan Wilhelm
}

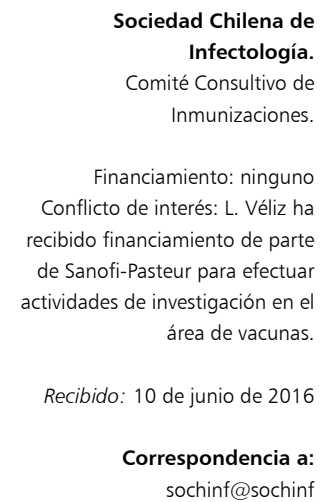

sochinf@sochinf

\author{
Reasons to recommend vaccination against dengue in Easter Island. \\ Immunization Advisory Committee of Sociedad Chilena de Infectología
}

Dengue was first diagnosed on Easter Island on year 2002 and thereafter recurrent outbreaks have occurred involving different serotypes of dengue virus. Its vector, Aedes aegypti has not been eliminated despite the small size of the island. Conditions at the local hospital preclude adequate management of severe and hemorrhagic cases due to the absence of a Critical Care Unit as well as no availability of platelets, or plasma units for transfusion. Besides, transfer, of severely affected patients to continental Chile is cumbersome, slow and expensive. In this scenario, it is advisable to implement selective vaccination of Easter Island habitants with an available quadrivalent attenuated dengue vaccine with the aim to reduce hemorrhagic and severe dengue cases. This strategy should not replace permanent efforts to control waste disposal sites, water sources, maintain vector surveillance and increase education of the population.

Key words: Dengue, dengue vaccines, Easter Island, prevention.

Palabras clave: Dengue, vacunas de dengue, Isla de Pascua, Rapa Nui, prevención.

L a Isla de Pascua o Rapa Nui, está ubicada en la Polinesia en medio del océano Pacífico a 3.526 $\mathrm{km}$ de la costa chilena $\left(27^{\circ} 7^{\prime} 10^{\prime \prime} \mathrm{S} 109^{\circ} 21^{\prime} 17^{\prime \prime} \mathrm{O}\right)$. Tiene una superficie de $163 \mathrm{~km}^{2}$, su altura máxima es de $511 \mathrm{~m}$ y todos los habitantes residen en su capital. $\mathrm{Su}$ posición geográfica determina un clima tropical con temperaturas suaves todo el año, sin heladas o fríos extremos. La temperatura promedio anual es de $20,5^{\circ} \mathrm{C}$ con un promedio máximo en febrero $\left(23,7^{\circ} \mathrm{C}\right)$ y un valor mínimo en agosto $\left(18,0{ }^{\circ} \mathrm{C}\right)$. Durante todo el año hay precipitaciones con un promedio de 1.124 $\mathrm{mm}$ (rango 73,1 a 127,9 $\mathrm{mm}$ de agua mensuales). Isla de Pascua tiene vuelos comerciales diarios de ida y vuelta a Chile continental y además vuelos frecuentes hacia la Polinesia. También recibe viajeros en barcos de turismo. Hacia el año 2013 se registraron 152.593 viajes aéreos entre Santiago e Isla de Pascua, 7.052 con Tahití y 3.698 con Perú 1 .

Las condiciones climáticas, características y posición geográfica de Isla de Pascua permiten la mantención de Aedes aegypti, vector de cuatro enfermedades por arbovirus (arthropod borne virus): fiebre amarilla, zika, chikungunya y dengue. Este mosquito vector está presente en Isla de Pascua desde el año 2000 y no ha podido ser eliminado. Todas las conexiones aéreas permiten traslado de pasajeros en tiempos menores a los períodos de incubación de estas cuatro enfermedades (rango 3 a 12 días) y el volumen anual de pasajeros facilita la introducción frecuente del riesgo desde pasajeros asintomáticos o sintomáticos.

Tres de las cuatro infecciones arbovirales han sido identificadas en Isla de Pascua, dos de ellas por transmisión local (dengue y zika) y chikungunya en viajeros provenientes de Tahíti $i^{2-4}$. Los primeros casos de dengue fueron registrados el año 2002 con reapariciones el 2006-2007, 2008, 2009, 2011 y 2016. Así, el MINSAL informa que al 10 de abril del presente año ya van 28 casos confirmados de dengue en Isla de Pascua 5 . Por su parte los casos de zika fueron registrados el 2014. Modelos matemáticos alimentados con los datos iniciales de dengue estiman brotes recurrentes de dengue a intervalos de pocos años $(<6)$ de magnitud decreciente y además permiten establecer que una alta tasa de personas fue infectada (> 90\%) ya sea en forma sintomática o asintomática durante el primer brote el año $2002^{4}$. En línea con esta información, al menos el $17 \%$ de la población fue afectada clínicamente durante el primer brote 4 .

El serotipo 1 (DENV1) fue identificado en los primeros brotes de dengue y luego se han registrado infecciones por el serotipo DENV4 el 2009, lo que reviste especial importancia ya que las reinfecciones por serotipos distintos aumentan el riesgo de dengue grave.

Las condiciones locales en la Isla para el diagnóstico y luego el manejo de cuadros graves no son adecuadas. Actualmente existe capacidad de diagnóstico serológico (ELISA IgM) para dengue pero no puede ser aplicada en 
los primeros días de evolución porque entrega valores falsamente negativos. El diagnóstico por reacción de polimerasa en cadena-transcriptasa reversa (RPC-TR) tiene mejor sensibilidad y puede ser aplicado para dengue, zika o chikungunya pero depende del envío de las muestras al ISP en Santiago por lo que existe una latencia relevante para el manejo apropiado, especialmente si se considera la gran sobreposición sindromática entre las infecciones arbovirales. Así, la simple presencia de fiebre, mialgias, artralgias y exantema, no permite discriminar entre las tres arbovirosis ya descritas en Isla de Pascua.

Con relación a la atención de pacientes, el Hospital Hanga Roa de Isla de Pascua es un centro de baja complejidad contando con 10 camas en cuidados básicos y otras cuatro de estabilización. Si bien dispone de ventiladores mecánicos, monitores y bombas de infusión, no cuenta con una UCI (Comunicación personal de Dra. Patricia Navarrete, Gestión Procesos Asistenciales, MINSAL, Chile). En él se efectúan estudios de imágenes y pruebas de laboratorio adaptadas a su perfil, incluyendo algunos estudios microbiológicos. Tiene una unidad de medicina transfusional de tipo IV que sólo aplica transfusiones de eritrocitos pero no de otros productos (plasma fresco congelado o plaquetas) y no posee atención de donantes (Comunicación personal de Sra. Ana Jara, Coordinación Nacional de Servicios de Sangre, MINSAL, Chile). De esta manera, aunque el hospital local está capacitado para el manejo de la mayor parte de los casos de dengue, está menos adaptado para casos de dengue grave con necesidades transfusionales y de medicina intensiva. Aproximadamente $10 \%$ de los casos de dengue en zonas endémicas es grave, caracterizado por shock, sobrecarga de volumen que pueden llevar al distress respiratorio, hemorragias o compromiso orgánico hepático, neurológico, cardiaco o en otros sitios ${ }^{6,7}$. La letalidad general del dengue bordea el $1 \%$ y aumenta a $2,5 \%$ en los casos graves ${ }^{6}$. Se debe mencionar que cada evacuación aeromédica tiene un costo aproximado de 25 millones de pesos chilenos (aproximadamente US\$ 36.000) y no es inmediata.

Los esfuerzos para controlar el vector han sido frustrantes, contribuyendo a ello el clima, el crecimiento poblacional y la conducta humana. Aedes aegypti es una especie "doméstica" ya que todas sus formas se encuentran cerca del hábitat humano: huevo, larva, pupa y adultos, incluyendo hembras y machos. La hembra se alimenta especialmente de sangre humana (antropófila) y este mosquito raras veces se encuentra a más de 100 metros de las casas. Los huevos pueden resistir largos períodos de sequedad y son depositados en superficies que probablemente serán inundadas en forma transitoria como agujeros en árboles, tuberías, jarras, maceteros, baldes, tambores, estanques, botellas, neumáticos, etc. El adulto de $A$. aegypti representa la fase reproductora del insecto. Por lo general, la hembra efectúa la ovipostura después de cada ingestión de sangre pero suele distribuir cada lote de huevos entre varios recipientes por lo cual una sola hembra puede originar varios focos. Los mosquitos adultos pueden vivir en la naturaleza, en promedio, 30 a 35 días. La temperatura óptima para la sobrevivencia de especímenes adultos oscila entre 23 y $25^{\circ} \mathrm{C}$. El uso de nuevos sistemas de control vectorial basados en la introducción de poblaciones de $A$. aegypti modificadas genéticamente parece interesante en Isla de Pascua por su aislamiento y tamaño reducido. Así, la inyección de machos portadores de un transgen letal dominante que se transmite a la progenie luego del apareamiento con la hembra mosquito ha logrado disminuir la población del vector en escenarios controlados y delimitados pero luego de varias introducciones y después de varias semanas ${ }^{8,9}$. Esta estrategia aún está en fase de desarrollo y no podemos contar con ella en el corto plazo para el control de nuestras infecciones arbovirales.

La población de Isla de Pascua ha crecido dramáticamente en los últimos años, convirtiéndose en la zona con mayor crecimiento inter-censal del país. La población el año 2002 era de 3.765 habitantes, cifra que aumentó a 5.806 habitantes el 2012, representando 54,2\% de crecimiento. La cifra actual se estima en unos 7.000 habitantes. Este aumento poblacional ha traído problemas con el manejo de la basura y con la provisión de agua potable mediante una red urbanizada lo que ha motivado el uso de estanques de acopio de agua en la zona suburbana. Ambos factores contribuyen a la creación y persistencia de focos de A. aegypti.

En este escenario de dengue endémico en la Isla de Pascua, con aparición de diferentes serotipos, perpetuación del vector sin lograr su control ambiental, limitaciones diagnósticas y de manejo para los casos más graves, es recomendable considerar seriamente la vacunación contra esta enfermedad en la población residente.

La vacuna disponible actualmente contra el dengue es una vacuna atenuada tetravalente (CYD-TDV: Chimeric Yellow Fever 17D Tetravalent Dengue Vaccine, Sanofi Pasteur) que ha demostrado en ensayos de campo en Latinoamérica y el Sudeste Asiático eficacias protectoras cercanas al $60 \%$ para dengue sintomático, $95 \%$ para casos graves y $80 \%$ para hospitalizaciones ${ }^{10,11}$. La vacuna ha sido diseñada a partir de la vacuna atenuada contra fiebre amarilla, en la que se han reemplazado los genes de premembrana y envoltura por aquellos de los cuatro serotipos silvestre de virus dengue. La vacuna, por su naturaleza atenuada, no ha sido aplicada en personas con inmunosupresión, embarazo o potencial de quedar embarazada durante el año que dura la aplicación de las 3 dosis a los 0, 6 y 12 meses por vía subcutánea.

Esta vacuna es poco reactogénica y la frecuencia de eventos adversos graves es menor a $1 \%$ y similar a lo medido en el grupo placebo ${ }^{11}$. Entre los 13.915 pacientes que recibieron al menos una dosis en Latinoamérica, cuatro tuvieron eventos adversos graves atribuidos a ella, que incluyeron una crisis moderada de asma, alergia urticarial con la segunda dosis, polineuropatía periférica 
con meningitis viral sin detección del virus vaccinal y un episodio de crisis convulsiva en el primer día de la primera dosis ${ }^{11}$. Al igual que en el caso de otras vacunas parenterales, los pacientes vacunados con este preparado expresan reactogenicidad local con dolor, edema o eritema o sistémica con fiebre, cefalea o mialgias ${ }^{6,7}$.

El seguimiento a seis años ha demostrado que los niños bajo 9 años de edad, vacunados, tienen un incremento de hospitalizaciones por dengue grave, respecto al grupo placebo, específicamente entre los 2 y 5 años ${ }^{12}$. Ello ha llevado a no recomendar la vacuna en este grupo etario por ahora. La eficacia de la vacuna es también modulada por la seroprevalencia basal en la población vacunada y por el serotipo. Así, la eficacia reportada es mayor en el grupo con evidencia de infección previa (81,9 versus $52,2 \%$ en el grupo seronegativo basal, respectivamente, en mayores de 9 años) ${ }^{12}$. Este dato es relevante para la decisión sobre Isla de Pascua por la estimación de una alta seroprevalencia basal debido a la tasa de ataque clínico observada el año 2002 y la relación entre casos sintomáticos y asintomáticos. De la misma manera, la protección conferida para infecciones por el serotipo 4 es mayor que para el resto de los serotipos mientras que el serotipo 2 logra menor respuesta inmune $(83,2 \%$ para DENV4; $73,6 \%$ para DENV3; $58,4 \%$ para DENV1 y $47,1 \%$ para DENV2 $)^{12}$. La eficacia de la vacuna a largo plazo aún no ha podido ser establecida y así mismo la experiencia en personas mayores de 45 años es muy limitada.

Así, la evidencia comentada junto a la persistencia del vector transmisor en Isla de Pascua, la condición endémica del dengue con cambios en los serotipos y las limitaciones locales para manejar casos graves, hacen prudente recomendar la vacunación selectiva de los residentes de esta isla con la vacuna YFD-TDV. Los grupos potenciales serían personas de 9 a 45 años de edad, sin inmunosupresión co- nocida y, en el caso de las mujeres, aquellas sin menarquía o con método anticonceptivo en uso. Por tratarse de una vacuna atenuada, la indicación debe ser evaluada por un médico. El objetivo primario es evitar hospitalizaciones y casos de dengue grave. Esta conclusión está en línea con las recomendaciones del Grupo Asesor Estratégico de Expertos en Inmunizaciones de la OMS (Strategic Advisory Group of Experts on Immunization: $S A G E)^{13}$.

La vacunación contra el dengue no reemplaza medidas esenciales de prevención contra la infestación del vector que está asociada a la transmisión de cuatro infecciones arbovirales. A pesar de la persistencia del vector, los esfuerzos para educar a la población, prevenir las picaduras, controlar los focos de infestación y ejecutar vigilancia entomológica deben mantenerse y ser reforzados.

Santiago, junio de 2016

\section{Resumen}

El dengue surgió el año 2002 en Isla de Pascua y se ha presentado en brotes intercurrentes desde entonces con aparición de diferentes serotipos. El vector Aedes aegypti no ha logrado ser eliminado a pesar del pequeño tamaño de la isla y las condiciones del hospital local no permiten el manejo de casos graves por ausencia de una unidad de cuidados intensivos y disponibilidad de transfusiones de plaquetas o plasma fresco congelado. Además, el traslado de pacientes graves hacia el continente no es inmediato y es muy costoso. En este escenario, es aconsejable vacunar selectivamente a la población residente con la vacuna cuadrivalente atenuada para disminuir la probabilidad de dengue grave. Esta estrategia no debe reemplazar los esfuerzos para el control de basurales, fuentes de agua, vigilancia del vector y educación de la población.

\section{Referencias bibliográficas}

1.- INE-Sernatur. Turismo. Informe anual 2013. Disponible en: http:/www.ine.cl/canales/menu/ publicaciones/calendario_de_publicaciones/pdf/ turismo_2013.pdf

2.- INE-ISP. Chikungunya. Boletín Instituto de Salud Pública de Chile Vol 5 Número 6 Junio 2015. Disponible en: http://www.ispch.cl/sites/ default/files/Chikungunya-21072015A.pdf

3.- Tognarelli J, Ulloa S, Villagra E, Lagos J, Aguayo C, Fasce R, et al. A report of the outbreak of zika virus on Eastern Island, south Pacific, 2014. Arch Virol 2016; 161: 665-8.

4.- Canals M, González C, Canals A M, Figueroa D. Dinámica epidemiológica del dengue en Isla de Pascua. Rev Chilena Infectol 2012; 29: 388-94.

5.- MINSAL Notifica nuevos casos de dengue en Isla de Pascua. Disponible en: http:/web.minsal. $\mathrm{cl} /$ ministerio-de-salud-informa-sobre-nuevo- caso-de-dengue-en-rapa-nui/

6.- Mallhi T H, Khan A H, Adnan A S, Sarriff A, Khan Y H, Jummaat F. Clinico-laboratory spectrum of dengue viral infection and risk factors associated with dengue hemorrhagic fever: a retrospective study. BMC Infect Dis 2015; 15: 399.

7.- Yacoub S, Mongkolsapaya J, Screaton G. Recent advances in understanding dengue. F1000 Research 2016, 5 (F1000 Faculty Rev): 78 Last updated: 15 FEB 2016.

8.- Harris A, McKemey AR, Nimmo D, Curtis Z, Black I, Morgan SA, et al. Successful suppression of a field mosquito population by sustained release of engineered male mosquitoes. Nat Biotechnol 2012; 30: 828-30.

9.- Alphey L, McKemey A, Nimmo D, Oviedo M N, Lacroix R, Matzen K, et al. Genetic control of Aedes mosquitoes. Pathog Glob Health 2013; 107: 170-9.
10.- Da Costa V G, Marques-Silva A C, Floriano V G, Moreli M L. Safety, immunogenicity and efficacy of a recombinant tetravalent dengue vaccine: a meta-analysis of randomized trials. Vaccine 2014; 32: 4885-92.

11.- Villar L, Dayan G H, Arredondo-García J L, Ribera D M, Cunha R, Deseda C, et al. Efficacy of a tetravalent dengue vaccine in children in Latin America. N Engl J Med 2015; 372 : 113-23.

12.- Hadinegoro S R, Arredondo-García J L, Capeding M R, Deseda C, Chotpitayasunondh $\mathrm{T}$, Dietze R, et al. Efficacy and long-term safety of a dengue vaccine in regions of endemic disease. N Engl J Med 2015; 373: 1195-206.

13.- OMS. Summary of the April 2016 meeting of the Strategic Advisory Group of Experts on Immunization. Disponible en: http://www.who. int/immunization/sage/meetings/2016/april/ SAGE April 2016 Meeting Web summary. pdf 